\title{
PYRAZOLINES WITH ANTICONVULSANT AND MAO INHIBITORY ACTIVITIES
}

\section{BY}

Mohamed Nabil Aboul-Enein ${ }^{1 *}$, Aida Abd El-Sattar El-Azzouny ${ }^{1}$, Kamilia M. Amin ${ }^{2}$, Youssreya A. Maklad ${ }^{1}$, Mohamed Ibrahim Attia ${ }^{1}$, and Mohammed Farrag El-Behairy ${ }^{1}$.

\section{FROM}

${ }^{1}$ Medicinal and Pharmaceutical Chemistry Department, Pharmaceutical and Drug Industries Research Division, National Research Centre, Dokki, Giza,12622, Egypt ${ }^{2}$ Department of pharmaceutical Chemistry, Faculty of Pharmacy, Cairo University, Cairo, Egypt

Corresponding author: Mohamed Nabil Aboul-Enein,

\section{ABSTRACT:}

2-Pyrazolines (4,5-dihydro-1H-pyrazole) are an important class of five-membered heterocyclic compounds and were found to be vital building block in medicinal chemistry and led to the discovery of a number of bioactive derivatives. The recent significant anticonvulsant and MAO inhibitory bioactivities of a variety of 2-pyrazolines are reviewed and discussed.

\section{KEY WORDS:}

2-Pyrazolines, anticonvulsants, monoamine oxidase inhibitors

\section{PYRAZOLINES AS ANTICONVULSANTS:}

The first approach by Parmar et al. in 1974 (e.g. compound 1) revealed appreciable anticonvulsant activity, reflected by its ability to afford protection against PTZ-induced seizures in mice (Parmar 1974).

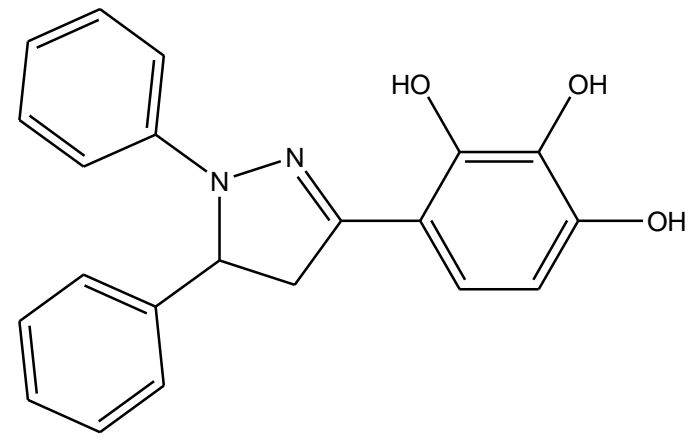

1

In a further work in Parmer group by Singh et al. In 1974, several 3-(3acetoamino)phenyl-1,5-substituted-2-pyrazolines have been prepared. All substituted pyrazolines exhibited anticonvulsant activity, which was reflected by $30-80 \%$ protection 
observed against pentylenetetrazole-induced seizures. Compound 2 showed the highest protection $(80 \%)$ at $100 \mathrm{mg} / \mathrm{kg}$ (Singh 1974).

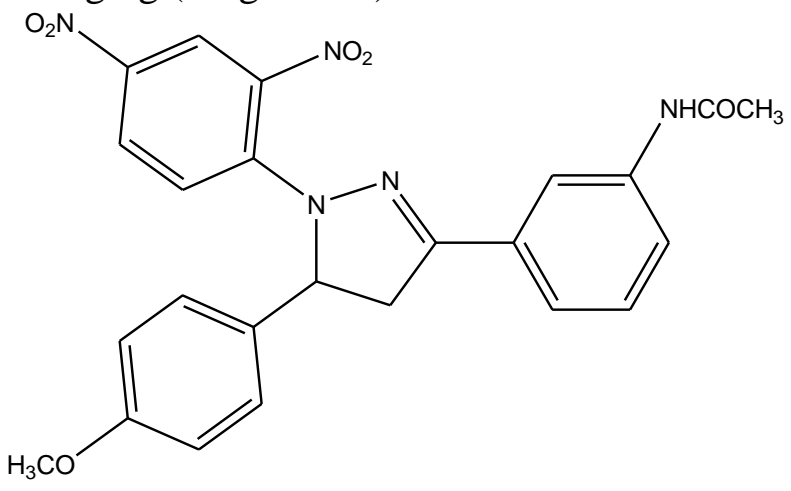

2

Later on, Pandey et al. (Pandey 1979) have prepared a series of 1,3-disubstituted5-(2-arylindol-3-yl)-2-pyrazolines. The new compounds at a dose of $100 \mathrm{mg} / \mathrm{kg}$ i.p. had anticonvulsant activity in mice. The degree of protection against PTZ-induced convulsions was $10-60 \%$. Compound $\mathbf{3}$ was the most active compound.

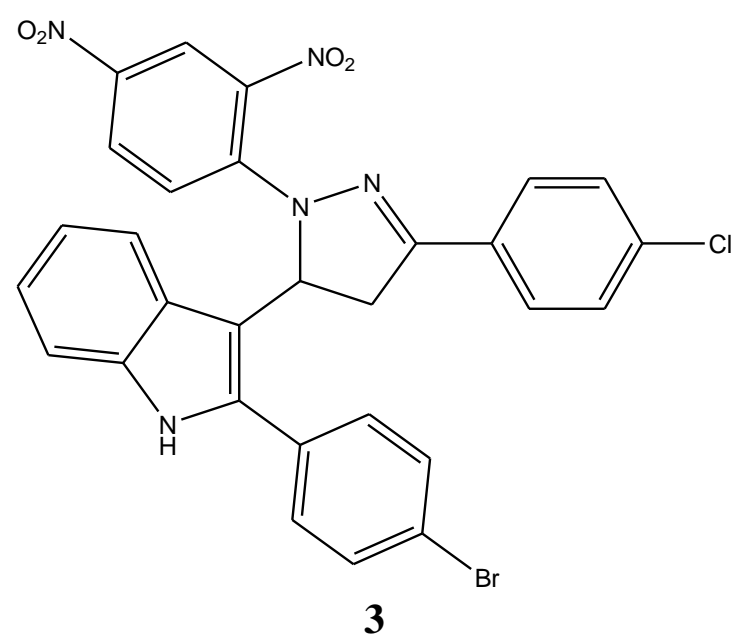

The single study in the eighties has been performed by Soni et al. in 1987. They have synthesized a series of 1,5-diaryl substituted-3-(4-chloro phenyl)-2-pyrazoline in which compound 4 provided $20-80 \%$ protection at $100 \mathrm{mg} / \mathrm{kg}$ against PTZ-induced

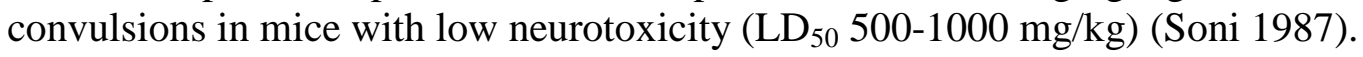

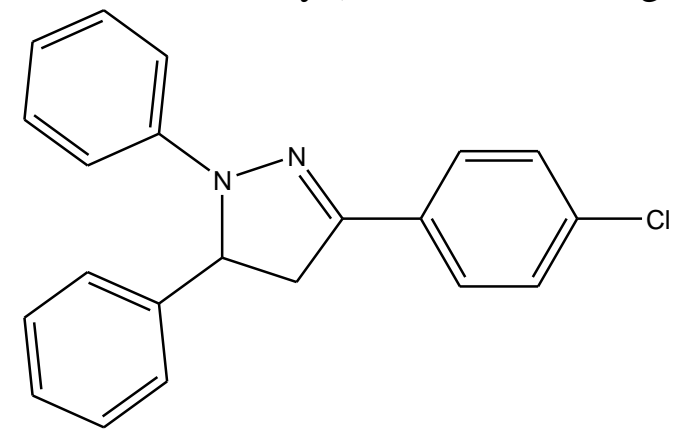


Applying a hybrid pharmacophoric model, Archana et al. have performed two studies in 2002. In the first study (Archana 2002), they have prepared a series of quinazolinonyl pyrazolines where compound $\mathbf{5}$ was the most active congener and showed anticonvulsant activity (90\%) more than the standard drug phenytoin sodium (80\%).

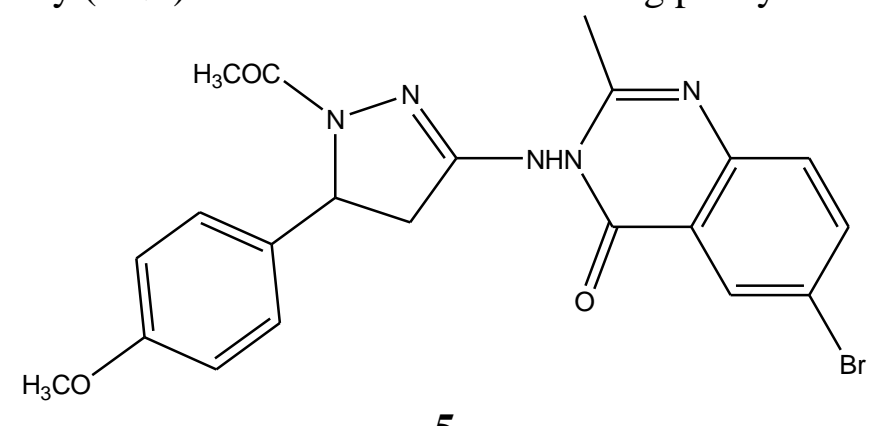

5

In the second study (Archana 2002), a series of 1-acetyl-5-aryl-3-(2'oxo/thiobarbiturinyl)-2-pyrazolines has been synthesized. The synthesized compounds showed anticonvulsant activity ranging from $40 \%$ to $90 \%$. Compound 6 showed the maximum activity being more potent than the reference drug.

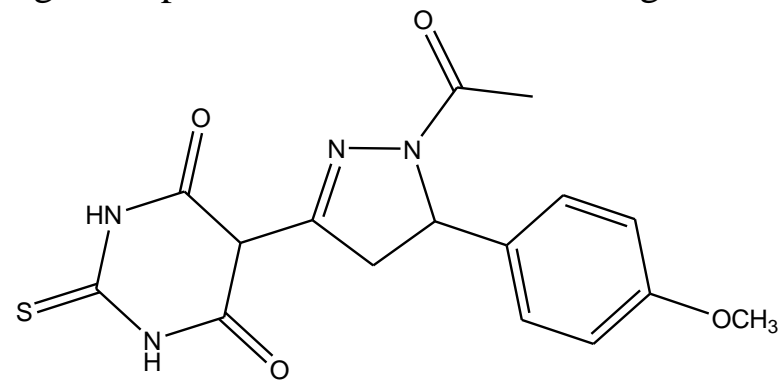

6

In 2007, Ozdemir et al. have prepared a series of 3-(2-furyl)-pyrazolines (O”zdemir 2007). Their anticonvulsant activity was determined by MES and scPTZ tests using albino mice. Compound 7 showed anticonvulsant activity against MES at 100 $\mathrm{mg} / \mathrm{kg}$.

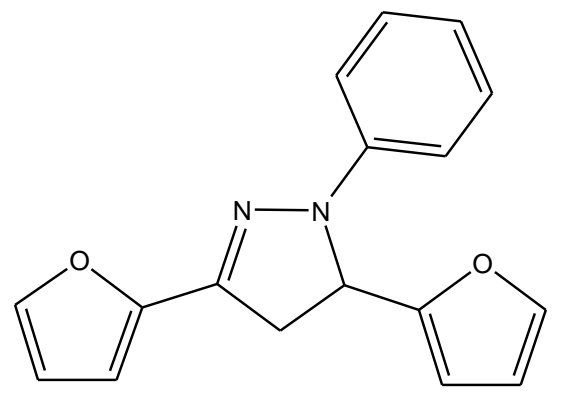


Another series of novel benzoxazole and benzimidazole pyrazolines has been prepared by Pujar et al. in 2008 and screened for in vivo anticonvulsant activity by PTZ induced convulsion in albino mice using diazepam as standard. Among tested compounds, compound 8 exhibited significant anticonvulsant effect (Pujar 2008).

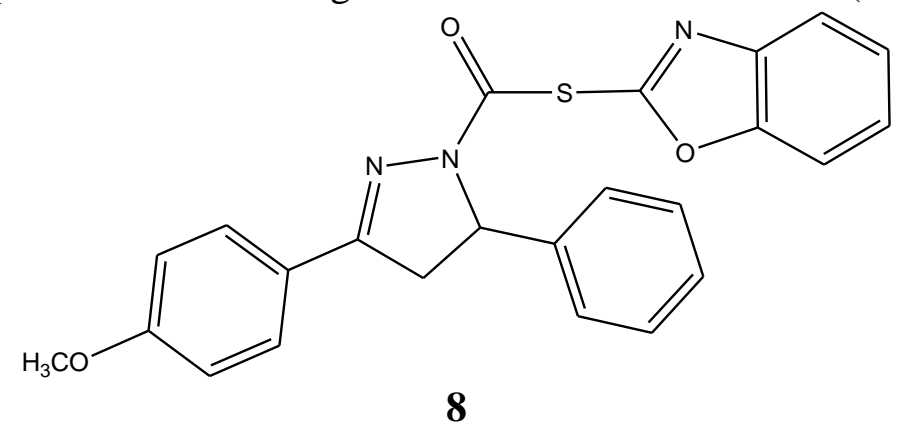

Siddiqui et al. in 2010 have synthesized a series of 3,5-diphenyl-2-pyrazoline-1carboxamide derivatives to be evaluated for their anticonvulsant activity by MES method. The preliminary results showed that all of the tested compounds were protective against MES at $100-300 \mathrm{mg} / \mathrm{kg}$ dose levels. Compound 9 was the most protective against MES even at $30 \mathrm{mg} / \mathrm{kg}$ dose levels (Siddiqui 2010).

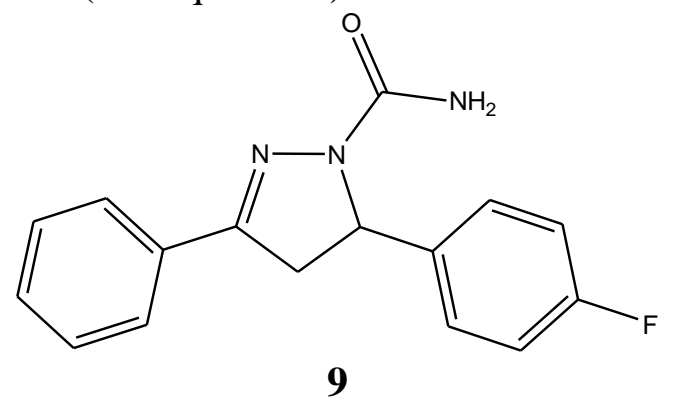

Through combining the anticonvulsant properties of aminobenzothiazole and pyrazolines, Amnerkar et al. in 2010 have prepared a series of 2-pyrazolin-3-yl aminobenzothiazole. The synthesized compounds were evaluated experimentally against MES test. The most active compound 10 exhibited $\mathrm{ED}_{50}$ of $25.49 \mathrm{mmol} / \mathrm{kg}, \mathrm{TD}_{50}$ of $123.87 \mathrm{mmol} / \mathrm{kg}$ and high protective index (PI) of 4.86 (Amnerkar 2010).

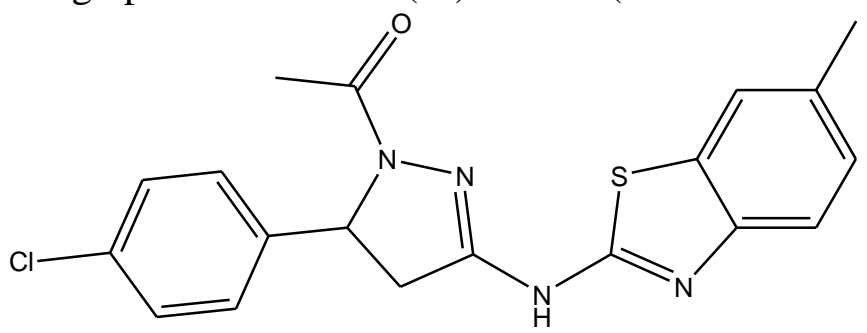

10 


\section{Pyrazolines with monoamine oxidase inhibitory activity:}

Inhibitors of monoamine oxidase have shown therapeutic value in a variety of neurodegenerative diseases (Youdim 2006). The discovery in the 1950s of the antidepressant properties of MAO inhibitors (MAOIs) was the major finding that led to the monoamine theory of depression. Earlier MAO inhibitors introduced into clinical practice for the treatment of depression were abandoned due to adverse side-effects, such as hepatotoxicity, orthostatic hypotension and the so-called 'cheese effect' characterized by hypertensive crises (Coutts 1986). This handicap was thought to be related to nonselective and irreversible monoamine oxidase inhibition. However, more recently, a better knowledge of the enzyme, in particular the identification of two isoforms (MAO-A and MAO-B) that can be selectively inhibited and the development of new generations of inhibitors have led to a renewed interest in the therapeutic potential of these compounds. These two forms of MAO are characterized by their different sensitivities to inhibitors and their different specificities to substrates. MAO-A preferably metabolizes serotonin, adrenaline, and noradrenaline (Johston 1968), whereas B-phenylethylamine and benzylamine are predominantly metabolized by MAO-B. Tyramine, dopamine, and some other important amines are common substrates for both isoenzymes. Nowadays, the therapeutic interest of MAOIs falls into two major categories. MAO-A inhibitors have been used mostly in the treatment of mental disorders, in particular depression and anxiety (Pacher 2004), while MAO-B inhibitors could be used in the treatment of Parkinson's disease and perhaps, Alzheimer's disease (Wouters 1998).

Studies by Parmar et al. and Soni et al. representing monoamine oxidase inhibitory activities of some 1,3,5-triphenyl-2-pyrazolines act as impetus for further research in this field (Parmar 1974) (Soni 1987). Thus, two series of 2-pyrazolines have been introduced by Palaska et al. in the first study, ten new 1,3,5-triphenyl-2-pyrazolines have been synthesized and evaluated for their antidepressant activities using 'Behavioural Despair Test'. Compound 11 reduced immobility time by $49.51 \%$ at $100 \mathrm{mg} \mathrm{kg}$ (Palaska 1996).

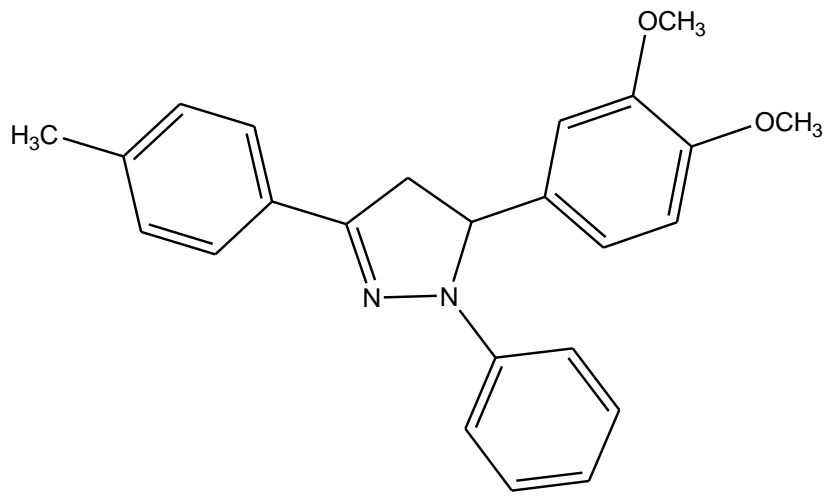

11

In the second study, a series of 3,5-diphenyl-2-pyrazolines has been synthesized. The antidepressant activities of the synthesized compounds were evaluated by the 'Porsolt Behavioural Despair Test' where compound $\mathbf{1 2}$ showed the best activity and reduced immobility time by $48.62 \%$ at $100 \mathrm{mg} \mathrm{kg}^{-1}$ (Palaska 2001). 


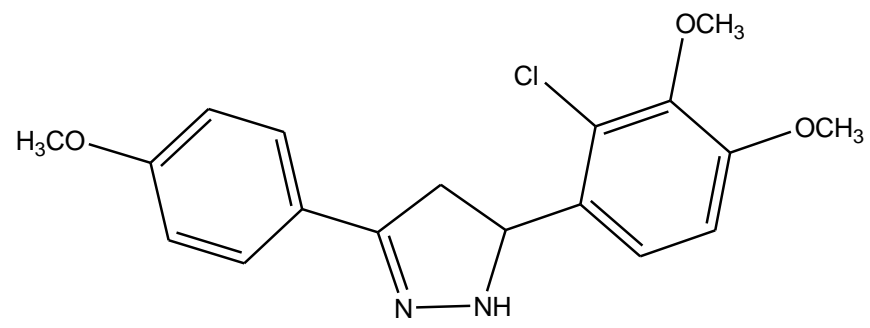

12

Further 1,3,5-tri-substituted 2-pyrazolines have been introduced by Prasad et al. Therefore, series of 3-(2-Naphthalen-1-yl)-1,5-diphenyl-2-pyrazolines has been prepared and evaluated by the Porsolt behavioural despair test. Compound $\mathbf{1 3}$ was the most active candidate showing 54.10\% reduction in the immobility time at $100 \mathrm{mg} / \mathrm{kg}$ (Prasad 2005).<smiles>Oc1ccc2ccccc2c1C1=NN(c2ccccc2)C(c2ccc(Br)cc2)C1</smiles>

13

In another study by Palaska et al. ten new 1-thiocarbamoyl-3-(phenyl and/or 4substituted phenyl)-5-(3,4-dimethoxyphenyl and/or 2-chloro-3,4-dimethoxyphenyl)-4,5dihydro-1H-pyrazole derivatives were synthesized and investigated for their ability to selectively inhibit monoamine oxidase (MAO-A) by in-vitro tests compared with pargyline and clorgyline. The monoamine oxidase-A inhibitory effects of 1thiocarbamoyl-3-(4-methoxyphenyl)-5-(3,4-dimethoxyphenyl)-4,5-dihydro-1H-pyrazole (14) and 1-thiocarbamoyl-3-(4-methoxyphenyl)-5-(2-chloro-3,4-dimethoxyphenyl)-4,5dihydro-1H-pyrazole (15) were found as potent as clorgyline (Palaska 2008).<smiles>COc1ccc(C2=NN(C(N)=S)C(c3ccc(OC)c(OC)c3)C2)cc1</smiles>

14<smiles>COc1ccc(C2=NN(C(N)=S)C(c3ccc(OC)c(OC)c3Cl)C2)cc1</smiles>

15 
Utilizing the multifunctional nature of pyrazolines with hydroxylphenyl substitution in 3rd and 5th position as metal chelating agents with antioxidant activity which are requirements in MOA-B selective inhibitors, Jayaprakash et al have tested series of 3,5-Diaryl carbothioamide pyrazolines against two isoforms of rat liver MAO-A and MAO-B. Compound $\mathbf{1 6}$ was found to be selective inhibitors of rat liver MAO-B $\left(\mathrm{IC}_{50}: 37.0 \pm 3.05 \mu \mathrm{M}\right)$ (Jayaprakash 2008).

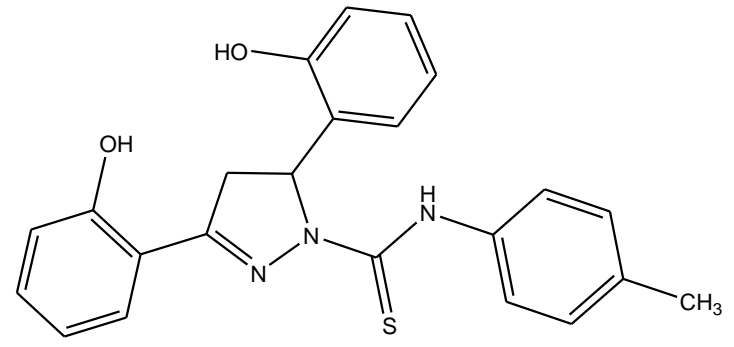

16

A new series of pyrazoline derivatives were prepared starting from a quinazolinone ring and evaluated for antidepressant, anxiogenic and MAO-A and -B inhibitory activities by in vivo and in vitro tests, respectively. Most of the synthesized compounds showed high activity against both MAO-A and MAO-B isoforms. Compound 17 was selective for MAO-B ( $\mathrm{IC}_{50: 2.03 \pm 0.27)}$ while compound 18 was selective for

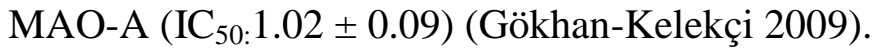

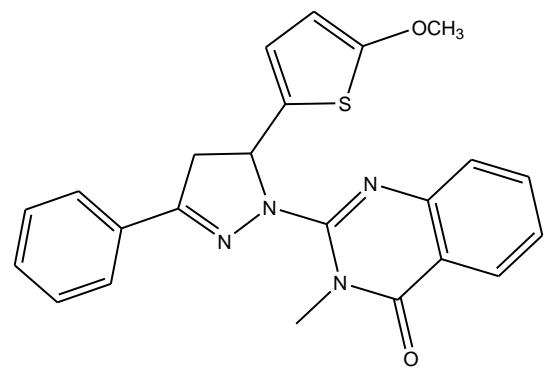

17

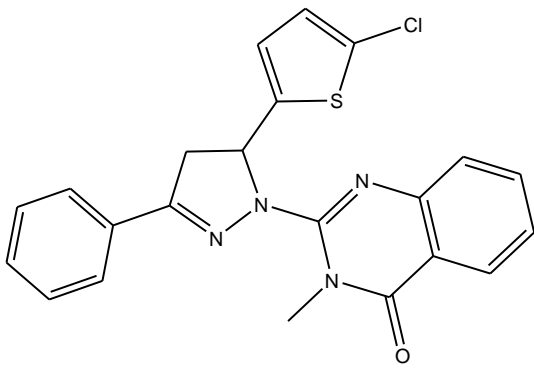

18

In 2010, Karuppasamy et al. have synthesized new series of 3,5-Diaryl pyrazolines and evaluated their monoamine oxidase (MAO) inhibitory activity. The compounds were found reversible and selective towards MAO-A with selectivity index in the magnitude of $10^{3}-10^{5}$. Compound 19 was the most active congener at $150.10 \pm 10.05$ nM (Karuppasamy 2010).

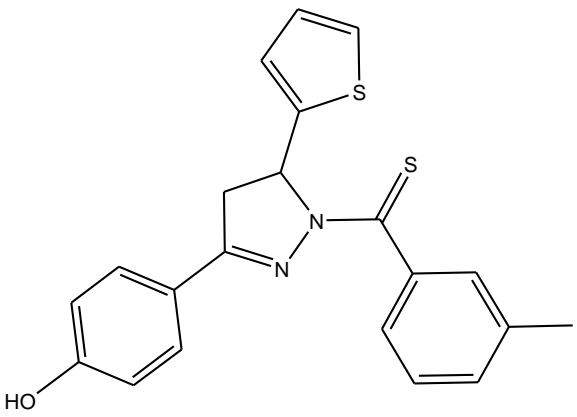


Advocated by the biological activity of some prenylated chalcones, Fioravanti et al. have prepared a series of N-substituted-3-[(2'-hydroxy-4'-prenyloxy)-phenyl]-5phenyl-4,5-dihydro- $(1 \mathrm{H})$-pyrazole and tested on human monoamine oxidase- $\mathrm{A}$ and $-\mathrm{B}$ isoforms. Comound 20 displayed the best activity against MOA-B $\left(\mathrm{pIC}_{50}=5.06 \mathrm{mM}\right)$ (Fioravanti 2010).

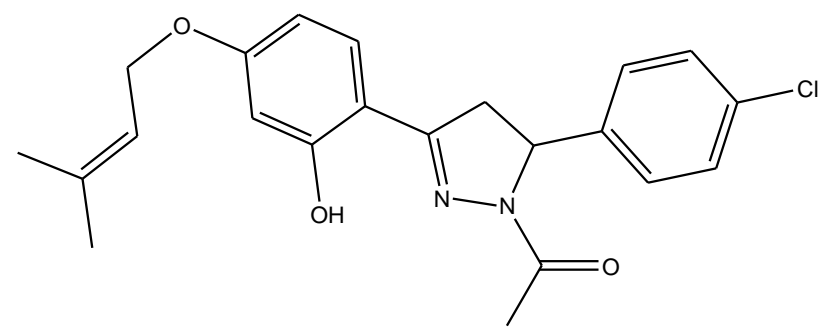

20

Good MAO-A inhibition and selectivity of N1-thiocarbamoyl-3,5-diaryl-4,5dihydro- $(1 \mathrm{H})$-pyrazoles motivated Chimenti et al. to synthesize a series of N1thiocarbamoyl-3,5-di(hetero)aryl-4,5-dihydro-(1H)-pyrazole derivatives and assay it for their ability to inhibit the activity of the A and B isoforms of human monoamine oxidase (hMAO). The most active of the series is the compound 21 with $\mathrm{IC}_{50} 2.75 \pm 0.81 \mathrm{mM}$ and selectivity ratio of 25 (Chimenti 2010).

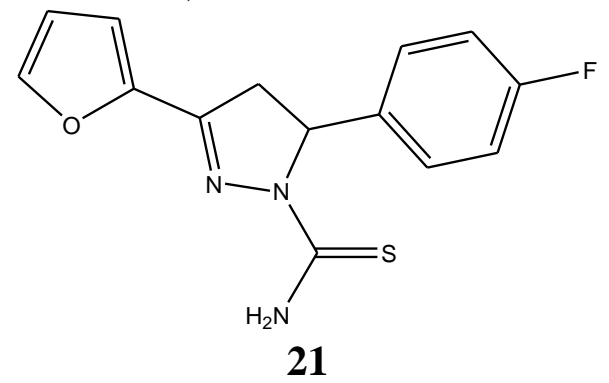

Further N1-thiocarbamoyl pyazolines have been prepared by Maccioni et al. and investigated their monoamine oxidase inhibitory activity. Compound $\mathbf{2 2}$ showed the highest selective MAO-B inhibitory activity (IC50 = $13.70 \pm 0.95 \mathrm{mM}$ ) (Maccioni 2010).<smiles>COc1ccc(C2=NN(C(=S)NO)CC2)cc1</smiles> 
In the same vein, eight new 1-[(N,N-disubstituted thiocarbamoylthio)acetyl]-3-(2thienyl)-5-aryl-2-pyrazolines have been synthesized and their antidepressant-like activity was investigated in mouse forced swimming test (FST). Compound $\mathbf{2 3}$ was found to be more effective in FST at $100 \mathrm{mg} / \mathrm{kg}$ than clomipramine and tranylcypromine used as reference antidepressant drugs (Gok 2010).

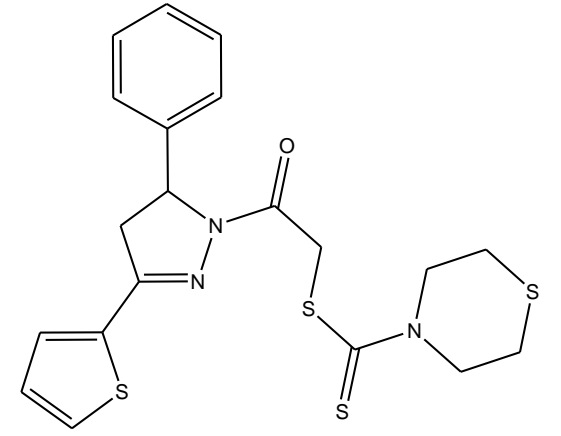

23

A hybrid series of the antidepressants triazoles and pyrazolines has been synthesized by Kaplanciklı et al. and investigated their potential antidepressant activities using both modified forced swimming and tail suspension tests. Compound $\mathbf{2 4}$ displayed the best activity being more active than Fluoxetine at $100 \mathrm{mg} / \mathrm{kg}$ (Kaplanciklı 2010).

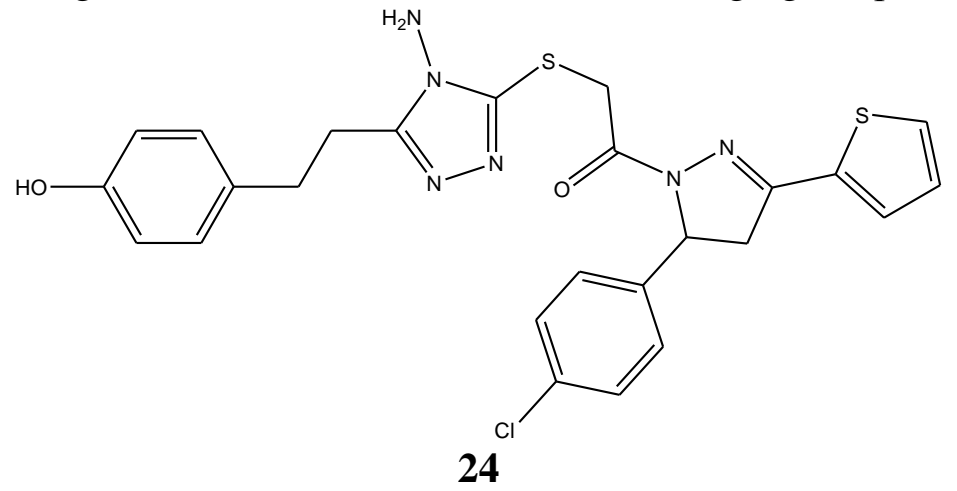

\section{REFERENCE:}

Amnerkar, N. D., Bhusar, K. P. (2010). "Synthesis, anticonvulsant activity and 3DQSAR study of some prop-2-eneamido and 1-acetyl-pyrazolin derivatives of aminobenzothiazole." Euro J Med Chem 45: 149-159.

Archana, A., Srivastava, V. K., Chandra, R., Kumar, A. (2002). "Synthesis of quinazolinonyl pyrazolines and quinazolinonyl isoxazolines as potential anticonvulsant agents." Indian Journal of Chemistry, Section B: Organic Chemistry Including Medicinal Chemistry 41: 2371-2375.

Archana, A., Srivastava, V. K., Kumar, A. (2002). "Synthesis and anticonvulsant activity of 1-acetyl-5-arylidenyl-3-(2'-oxo/thiobarbiturinyl)-2-pyrazolines." Arzneimittelforschung 52: 787-791.

Chimenti, F., CarraS., Secci, D., Bolasco, A., Bizzarri, B., Chimenti P., Granese, A., Yanez, M., Orallo, F. (2010). "Synthesis and inhibitory activity against human monoamine oxidase of N1-thiocarbamoyl-3,5-di(hetero)aryl-4,5-dihydro- $(1 \mathrm{H})$ pyrazole derivatives." eur J Med Chem 45: 800-804. 
Coutts, R. T., Baker, G. B., Danielson, T. J., Ed. (1986). New Developments in Monoamine Oxidase Inhibitors. In Developments of Drugs and Modern Medicines. Part I. Drug Design. Chichester, Ellis Horwood Ltd: .

Fioravanti, R., Bolasco, A., Manna, A., Rossi, F., Orallo, F., Yáñez, M., Vitali, A., Ortuso, F., Alcaro, S. (2010). "Synthesis and molecular modelling studies of prenylated pyrazolines as MAO-B inhibitors." Bioorg. Med. Chem. Lett. 20: 6479-6482.

Gok, S., Murat Demet, M., O“ zdemir, A., Turan-Zitouni, G. (2010). "Evaluation of antidepressant-like effect of 2-pyrazoline derivatives." Med Chem Res 19: 94101.

Gökhan-Kelekçi, N., Koyunoglu, S., Yabanoglu, S., Yelekçi, K., Özgen, Ö., Uçar, G., Erol, K., Kendi, E., Yesßilada, A. (2009). "New pyrazoline bearing 4(3H)quinazolinone inhibitors of monoamine oxidase: Synthesis, biological evaluation, and structural determinants of MAO-A and MAO-B selectivity." Bioorg. Med. Chem. 17: 675-689.

Jayaprakash, V., Sinha, B. N., Ucar, G., Ercan, A. (2008). "Pyrazoline-based mycobactin analogues as MAO-inhibitors." Bioorg. Med. Chem. Lett. 18: 63626368.

Johston, J. P. (1968). "Some observations upon a new inhibitor of monoamine oxidase in brain tissue." Biochem. Pharmacol. 17: 1285-1297.

Kaplancıklı, Z. A., Özdemir, A., Turan-Zitouni, G., Altıntop, M. D., Can, O. D. (2010). "New pyrazoline derivatives and their antidepressant activity." Eur J Med Chem 45: 4383-4387.

Karuppasamy, M., Mahapatra, M., Yabanoglu, S., Ucar, G., Sinha, B. N., Basu, A., Mishra, N., Sharon, A., Kulandaivelu, U., Jayaprakash, V. (2010).

"Development of selective and reversible pyrazoline based MAO-A inhibitors: Synthesis, biological evaluation and docking studies." Bioorg. Med. Chem. 18: 1875-1881.

Maccioni, E., Alcaro, S.,Orallo, F., Cardia, M.C., Distinto, S., Costa, G., Yanez, M., Sanna, M.L., Vigo, S., Meleddu, R., Secci, D. (2010). "Synthesis of new 3-aryl4,5-dihydropyrazole-1-carbothioamide derivatives. An investigation on their ability to inhibit monoamine oxidase." Eur J Med Chem 45: 4490-4498.

O“zdemir, Z., Kandilci, H. B., Gu“mu“sel, B., Calısx, U., Bilgin, A. A. (2007). "Synthesis and studies on antidepressant and anticonvulsant activities of some 3(2-furyl)-pyrazoline derivatives." Euro J Med Chem 42: 373-379.

Pacher, P., Keckemeti, V. (2004). "Trends in the development of new antidepressants. Is there a light at the end of the tunnel?" Curr. Med. Chem. 11: 925-943.

Palaska, E., Aydin, F.,Ucar, G., Erol, D. (2008). "Synthesis and Monoamine Oxidase Inhibitory Activities of 1-Thiocarbamoyl-3,5-diphenyl-4,5-dihydro-1H-pyrazole Derivatives." Arch. Pharm. Chem. Life Sci. 341: 209-215.

Palaska, E., Aytemir, M., Uzbay, T. I., Erol, D. (2001). "Synthesis and antidepressant activities of some 3,5-diphenyl-2-pyrazolines." Eur. J. Med. Chem. 36: 539-543.

Palaska, E., Erol, D., Demirdamar, R. (1996). "Synthesis and antidepressant activities of 1,3,5-triphenyl-2-pyrazolines." Eur. J. Med. Chem. 31: 43-47. 
Pandey, B. R., Raman K., Barthwal J. P., Parmar S. S. (1979). "Central nervous system depressant activity of 1,3-disubstituted-5-(2-arylindol-3-yl)-D2pyrazolines." National Academy Science Letters (India) 2: 98-100.

Parmar, S. S., Pandey B. R., Dwivedi C., Harbison R. D., (1974). "Anticonvulsant activity and monoamine oxidase inhibitory properties of 1,3,5-trisubstituted pyrazolines." J Pharm Sci 63: 1152-1155.

Prasad, Y. R., Rao, A. L., Prasoona, L., Murali, K., Ravi Kumar, P. (2005).

"Synthesis and antidepressant activity of some 1,3,5-triphenyl-2-pyrazolines and 3-(2"-hydroxynaphthalen-1"-yl)-1,5-diphenyl-2-pyrazolines." Bioorg. Med. Chem. Lett. 15: 5030-5034.

Pujar, G. V., Synesh, C., Purohit, M. N., Srinivasalu, N., Udupi, R. H. (2008). "Synthesis, anticonvulsant, and antibacterial activities of some novel pyrazolines derived from benzoxazole and benzimidazole." Indian Journal of Heterocyclic Chemistry 17: 387-388.

Siddiqui, A. A., Azizur Rahman, M., Shaharyar, M., Mishra, R. (2010). "Synthesis And Anticonvulsant Activity Of Some Substituted 3,5-Diphenyl-2-Pyrazoline-1Carboxamide Derivatives." Chemical Sciences Journal, CSJ-8: in press.

Singh, S. P., Chaudhari A., Barthwal J. P., Parmar S. S., (1974). "Anticonvulsant activity and selective inhibition of nicotinamide adenine dinucleotide-dependent oxidations by 1,3,5-trisubstituted pyrazolines." J Pharm Sci 63: 1948-1950.

Soni, N., Pande, K., Kalsi, R., Gupta, T. K., Parmar, S. S., Barthwal, J. P. (1987). "Inhibition of rat brain monoamine oxidase and succinic dehydrogenase by anticonvulsant pyrazolines." Res Commun Chem Pathol Pharmacol 56(1): 129132.

Wouters, J. (1998). "Structural aspects of monoamine oxidase and its reversable inhibition." Curr. Med. Chem. 5: 137-162.

Youdim, M. B. H., Edmonson, D., Tipton, K. F. (2006). "The therapeutic potential of monoamine oxidase inhibitors." Nat. Rev. Neurosci. 7: 295-309.

بعض مركبات البيرازولين الحلقي كمضادات للصرع و كمثبطات لانزيم (MAO)

$$
\begin{aligned}
& \text { للسادة الاكاترة }
\end{aligned}
$$

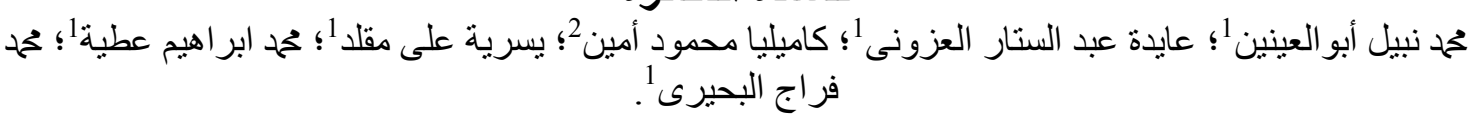

$$
\begin{aligned}
& \text { 1قسم الكيمياء الطبية و الصيدلية, شعبة بحوث الصناعات الصيدلية و الدوائية, المركز القومي للبحوث. }
\end{aligned}
$$

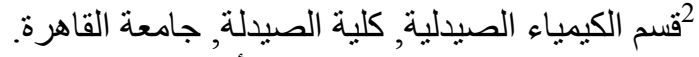

$$
\begin{aligned}
& \text { الباحث الرئيسي: عحم نبيل أبوالعينين }
\end{aligned}
$$

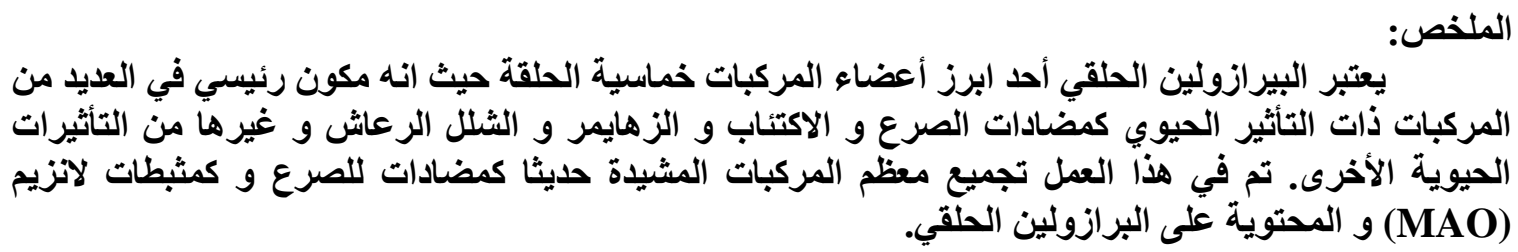

